\title{
Restructuration Fatty Acid Oil Castor Being Cocoa Butter Substitute Through Dehydration Reaction Castor Oil And This Interesterification With Coconut Oil
}

\author{
Sirait J Ribka and Marham Sitorus \\ Department of Chemistry, Faculty of Mathematics and Sciences, Medan State University, Medan 20221, \\ Indonesia \\ Email :sitorus.marham@gmail.com
}

\begin{abstract}
The purpose of this research to restructuring its acid fatty oils castor result of dehydration with coconut oil through the process interesterification to produce cocoa butter substitute (CBS). Coconut oil is obtained from coconut milk by heating it slowly over low heat. The resulting coconut oil has a FFA is 1.667\%, a peroxide is $10.229 \mathrm{MekO}_{2} / \mathrm{Kg}$ and an iodine is $7,7080 \mathrm{gI}_{2} / 100 \mathrm{~g}$, which meets the second quality standard according to SNI 01-3741-2002. The restructuring was carried out by interesterification of dehydrated castor oil with coconut oil with a ratio (50:50); (60:40); (70:30); (80:20) dan(90:10)with a $\mathrm{NaOCH}_{3}$ catalyst. The results showed that the interesterification of dehydrated castor oil with coconut oil with a ratio (50:50) was the most optimal ratio with a melting point of $33{ }^{\circ} \mathrm{C}$ which corresponds to cocoa oil $\left(32{ }^{\circ} \mathrm{C}-35^{\circ} \mathrm{C}\right)$ and contain omega-6 fats (linoleic acid).
\end{abstract}

Keywords: Castor oil, dehydrated coconut oil, Interesterification and Cocoa Butter Substitute.

\section{Pendahuluan}

Tanaman jarak (Ricinus Comunist L) merupakan spesies tanaman bernilai komersial sehingga banyak yang mengusahakannya. Hal ini disebabkan karena biji jarak jenis ini memiliki kadar minyak yang sangat tinggi yaitu antara 40$55 \%$. Tanaman ini dapat tumbuh dengan cepat dan dapat memperbanyak diri dengan bijinya. Mulamula tanaman Jarak ini berasal dari Ethopia yang selanjutnya tersebar hampir di semua daerah baik yang beriklim panas maupun sedang terutama di benua Asia, Amerika dan Afrika ${ }^{1}$. Sebagian besar dari tanaman jarak yang dijadikan komoditas utama adalah terletak pada bijinya. Biji Jarak tersebut dapat menghasilkan suatu minyak yang disebut dengan minyak jarak. Minyak jarak pada umumnya, sering dipergunakan sebagai untuk industry kosmetik, farmasi, minyak pelumas pada industry otomotif pengobatan dan militer ${ }^{2}$.

Minyak jarak adalah minyak nabati yang terdapat dalam biji jarak yang dapat diperoleh melalui proses pengepresan atau ekstraksi pelarut ${ }^{3}$. Sedangkan untuk analisis kandungan asam lemak minyak biji jarak menggunakan kromatografi gascair diperoleh asam risonoleat $87 \%$, asam palmitat $2 \%$, asam stearat $1 \%$, asam oleat $7 \%$, dan asam linoleat $3 \%{ }^{4}$.

Risinoleat adalah asam lemak dengan $\mathrm{C}_{18}$ mengandung satu ketidakjenuhan pada $\mathrm{C}_{9}$ dan gugus hidroksil pada $\mathrm{C}_{12}$. Risinoleat dengan nama 
kimia 12-hidroksi-9cis oktadekanoat merupakan satu-satunya komponen minyak jarak yang tidak essensial, maka bila dilakukann dehidrasi akan menjadikan semua komponen minyak jarak menjadi esensial, dengan demikian minyak jarak yang risinoleatnya menjadi dapat dikomsumsi (edible oil), sehingga akan menaikkan nilai ekonomis minyak jarak ${ }^{5}$.

Dalam minyak jarak, Risinoleat terdapat sebagai trigliserida (lemak) yang mempunyai tiga macam gugus fungsional, yaitu: ester dari gliserol, alkena dan hidroksil (alkohol). Untuk memisahkan campuran asam lemak dalam bentuk trigliseridanya terlebih dahulu dimetilesterkan secara esterifikasi maupun interesterifikasi ${ }^{1}$.

Risinoleat merupakan satu-satunya komponen minyak jarak yang tidak esensial, maka bila dilakukan dehidrasi akan menjadikan semua komponen minyak jarak menjadi esensial. Dengan demikian minyak jarak yang asam risinoleatnya menjadi dapat dikomsumsi (Edible), sehingga akan menaikkan nilai ekonomis minyak jarak. Minyak jarak hasil dehidrasi $(\mathrm{DCO}=$ Dehydrated Castor Oil) mengandung dua komponen utama yaitu linoleat dan asam linoleat terkonjugasi (CLA= Conjugated Linoleic Acid) dalam bentuk trigliserida. Linoleat (omega-6) dan linoleat terkonjugasi sangat terbatas sebarannya dialam sebagai nabati dan hewani padahal keduanya merupakan lemak esensial ${ }^{6}$.

Agar minyak kastor hasil dehidrasi dapat dimanfaatkan sebagai komsumsi, maka pada penelitian ini akan dilakukan restrukturisasi asam lemak penyusunnya melalui reaksi interestifikasi dengan minyak kelapa. Minyak kelapa kaya dengan asam lemak diharapkan dapat digunakan sebagai pengganti mentega kakao (Cocoa Butter Substituent $=$ CBS) yang komposisinya didominasi asam lemak tidak jenuh dan titik didih relative rendah $^{7}$. Selanjutnya hasil retrukturisasi minyak kastor hasil dehidrasi melalui interestifikasi dengan minyak kelapa yang kaya akan asam lemak jenuh rantai sedang yaitu asam laurat akan dapat dibuat menjadi pengganti mentega coklat atau Cocoa Butter Subsituent (CBS).

Pengganti lemak kakao yang dihasilkan dapat berupa lemak kakao eqivalen (Abigor, 2002) yaitu pengganti lemak kakao yang mempunyai sifat fisik dan kimia yang sama dengan lemak kakao, sedangkan pengganti lemak kakao subtitusi yaitu lemak kakao yang hanya sifat fisiknya saja mirip dengan lemak kakao. Kualitas yang baik dari lemak kakao adalah keras pada suhu kamar, mempunyai titik cair yang sama dengan temperatur tubuh, dan mempunyai derajat kompatibilitas dengan lemak kakao dan lemak susu ${ }^{8}$.

\section{Metodologi Penelitian}

2.1. Bahan kimia, peralatan dan instrumentasi Minyak kastor, minyak kelapa, aquades,Natrium Sulfat $\left(\mathrm{Na}_{2} \mathrm{SO}_{4}\right)$ anhidrat, $\mathrm{P}_{2} \mathrm{O}_{5}$, Natrium Metokdisa $\left(\mathrm{NaOCH}_{3}\right)$, asam sitrat $20 \%$, indikator PP, Kalium Hidroksida $(\mathrm{KOH})$, etanol $95 \%, \quad \mathrm{Na}_{2} \mathrm{~S}_{2} \mathrm{O}_{3} \quad 0,1 \quad \mathrm{~N}$, asam asetat glasial $\left(\mathrm{CH}_{3} \mathrm{COOH}\right)$, pereaksi wijs, Kalium Iodida (KI) 15\%, Kalium Iodida (KI) jenuh, pati 1\%. contoh: Atomic Absorption Spectroscopy (AAS; Varian SpectrAA-400 spectrometer).beaker glass, erlemeyer, pipet volemetrik, timbangan analitik, labu leher 3, hot plate stirrer, stirrer bar, refluks, buret, erlemeyer, corong pisah dan instumen GCMS

\subsection{Prosedur penelitian}

\section{Persiapan Sampel}

Minyak kastor sebanyak $1000 \mathrm{ml}$, diperoleh dari minyak kastor yang dijual dipasaran. Untuk minyak kelapa diambil dari kelapa tua yang kemudian di ambil dagingnya dan diparut.

\section{Pembuatan Minyak Kelapa}

Minyak kelapa dibuat secara tradisional, yaitu dengan cara daging buah kelapa yang telah diparut kemudian di press untuk mendapatkan santan murni yang kental. Kemudian dipanaskan dengan api kecil hingga minyak kelapa terpisah dari pengotornya. Hasil yaang didapat kemudian didinginkan dan disaring sehingga diperoleh minyak kelapa yang diinginkan.Minyak jarak yang digunakan adalah yang telah dimurnikan (Refined ricinus castor oil) dengan sifat fisik : warna kuning bening, bau khas biji jarak, berat jenis $0,951 \mathrm{~g} / \mathrm{mL}$ (Standar Nasional Indonesia/SNI : 0,957- 0,963 $\mathrm{g} / \mathrm{mL}$ ), larut sempurna dalam metanol (sesuai dengan SNI). Karakteristik (parameter kimia) dari minyak jarak yang ditentukan dengan metode titrasi (volumetri) adalah: kadar ALB/FFA 1,855\%, bilangan Iodium 49,860 $\mathrm{mg} / \mathrm{g}$ dan bilangan hidroksida 28,27 mg/g (Sitorus,dkk, 2009).

\section{Analisis Mutu Minyak}

Bilangan Iodium, Sebanyak kurang lebih 0,2 g bahan minyak ditimbang secara seksama, lalu dimasukkan dalam labu iodium (iodin flask). Larutan selanjutnya ditambah $10 \mathrm{~mL}$ kloroform 
dan $25 \mathrm{ml}$ pereaksi iodium-bromida dan dibiarkan ditempat gelap selama 30 menit dengan kadangkala digojog. Larutan kemudian ditambahkan $10 \mathrm{ml}$ larutan KI $15 \%$ dan $50 \mathrm{~mL}$ aquadest yang telah dididihkan, lalu dititrasi segera dengan larutan baku natrium tiosulfat $\left(\mathrm{Na}_{2} \mathrm{~S}_{2} \mathrm{O}_{3}\right)$ sampai larutan berwarna kuning pucat, lalu ditambahkan $2 \mathrm{ml}$ larutan pati $1 \%$, titrasi dilanjutkan sampai warna biru tepat hilang. Dilakukan juga titrasi blanko dengan cara: sebanyak $25 \mathrm{~mL}$ pereaksi iodiumbromida, ditambah $10 \mathrm{~mL}$ KI $15 \%$, $50 \mathrm{~mL}$ aquadest yang telah dididihkan dan dititrasi dengan $\mathrm{Na}_{2} \mathrm{~S}_{2} \mathrm{O}_{3}$ sampai larutan berwarna kuning pucat, lalu ditambahkan $2 \mathrm{ml}$ larutan pati $1 \%$, titrasi dilanjutkan sampai warna biru tepat hilang.

Asam Lemak Bebas, Sampel sebanyak 10-20 g dimasukkan ke dalam erlenmeyer $250 \mathrm{~mL}$, kemudian ditambahkan $50 \mathrm{~mL}$ etanol $95 \%$. Ke dalam campuran ditambahkan 3-5 tetes indikator phenoftalein. Selanjutnya dititrasi dengan larutan standar $\mathrm{KOH} 0.1 \mathrm{~N}$ hingga berwarna merah muda. Setelah itu dihitung jumlah $\mathrm{KOH}$ yang digunakan untuk titrasi dicatat untuk menghitung kadar asam lemak bebas.

Bilangan peroksida, Sebanyak 5 gram sampel dimasukkan ke dalam erlenmeyer $250 \mathrm{~mL}$, kemudian ditambahkan $30 \mathrm{~mL}$ campuran pelarut yang terdiri dari $60 \%$ asam asetat glasial dan $40 \%$ kloroform. Setelah minyak larut, ditambahkan $1 \mathrm{~g}$ KI sambil dikocok kemudian didiamkan selama 30 menit dalam tempat gelap. Setelah itu ditambahkan $30 \mathrm{~mL}$ aquades. Kelebihan iod dititrasi dengan larutan $0,1 \quad \mathrm{~N} \quad \mathrm{Na}_{2} \mathrm{~S}_{2} \mathrm{O}_{3}$ sampai warna kuning hampir hilang. Ditambahkan $0.5 \mathrm{~mL}$ larutan pati $1 \%$. Titrasi dilanjutkan sampai warna biru mulai hilang ${ }^{9}$.Hasilnya dinyatakan dalam miliekuivalen per 1000 gram minyak.

\section{Dehidrasi Minyak Kastor}

Sebanyak $200 \mathrm{~mL}$ minyak jarak dimasukkan ke dalam labu atas bulat leher tiga kapisitas $500 \mathrm{~mL}$. Selanjutnya ditambahkan $3 \%$ dehidrator $\mathrm{P}_{2} \mathrm{O}_{5}$ untuk kemudian direfluks dengan suhu $200{ }^{0} \mathrm{C}$ selama 4 jam dengan kecepatan pengadukan $800-1000$ rpm.

\section{Pembuatan Pengganti Mentega Coklat (Interesterifikasi)}

$50 \mathrm{~mL}$ minyak kelapa dimasukkan kedalam botol aspirator ditambahkan dengan $50 \mathrm{~mL}$ hasil dehidrasi dan ditambahkan katalis $\mathrm{NaOCH}_{3}$ sebanyak 0,3 gram. Campuran ini diaduk menggunakan pengaduk mekanik dengan kecepatan putaran 3000 rpm selama 4 jam. Setelah itu katalis diinaktivasi dengan menggunakan $20 \mathrm{ml}$ asam sitrat 20\%, kemudian dipisahkan dengan corong pisah (Tarigan, 2005). Interesterifikasi hasil dehidrasi dengan minyak kelapa dilakukan dalam perbandingan: (50:50); (60:40); (70:30); (80:20); $(90: 10) \% \mathrm{v} / \mathrm{v}$.

\section{Penentuan Titik Lebur Hasil Iteresterifikasi}

Hasil interesterifikasi dari berbagai perbandingan dipanaskan hingga mencair dan homogen. Asam lemak cair tersebut dimasukkan ke pipa kapiler setinggi $1 \mathrm{~cm}$, ujung pipa kapiler ditutup dan disimpan ke dalam lemari pendingin selama 24 jam. Pipa kapiler kemudian diikatkan pada ujung bawah thermometer sehingga bagian bawah pipa kapiler sejajar dengan ujung bawah termometer. Kemudian pipa kapiler ini dimasukkan kedalam erlemeyer yang berisi air sebanyak $400 \mathrm{~mL}$. ujung bawah pipa kapiler dimasukkan sedalam $3 \mathrm{~cm}$ dan erlemeyer dilengkapi dengan pengaduk magnet. Dipanaskan diatas hotplate, dicatat pada saat mana mulai mencair.

\section{Hasil dan Diskusi}

\subsection{Preparasi Sampel}

Santan Kelapa diperoleh dari Toko Kelapa Pasar Raya MMTC sebanyak 2L. Warna santan semula adalah putih seperti susu yang diperoleh dari daging buah kelapa tua. Santan kemudian diberi perlakuan yaitu pemanasan untuk menghasilkan minyak kelapa yang diinginkan. Warna santan setelah perlakuan menjadi kuning dan minyak yang dihasilkan sebanyak $750 \mathrm{~mL}$. Minyak jarak yang digunakan adalah yang telah dimurnikan (Refined ricinus castor oil) dengan sifat fisik : warna kuning bening, bau khas biji jarak, berat jenis $0,951 \mathrm{~g} / \mathrm{mL}$ (Standar Nasional Indonesia/SNI : 0,957- 0,963 $\mathrm{g} / \mathrm{mL}$ ), larut sempurna dalam metanol (sesuai dengan SNI). Karakteristik (parameter kimia) dari minyak jarak yang ditentukan dengan metode titrasi (volumetri) adalah: kadar ALB/FFA 1,855\%, bilangan Iodium $49,860 \mathrm{mg} / \mathrm{g}$ dan bilangan hidroksida $28,27 \mathrm{mg} / \mathrm{g}$ (*sumber : Sitorus,dkk, 2009).

\subsection{Uji Mutu Minyak}

Uji mutu minyak pada kedua minyak yang akan di interesterifikasi dapat dilihat padaTabel 1 . 
Tabel 1. Uji Mutu Minyak

\begin{tabular}{|c|c|c|}
\hline \multirow{2}{*}{ Jenis Uji Mutu Minyak } & \multicolumn{2}{|c|}{ Jenis Minyak } \\
\cline { 2 - 3 } & $\begin{array}{c}\text { Minyak } \\
\text { Kelapa }\end{array}$ & $\begin{array}{c}\text { Minyak } \\
\text { Kastor } \\
\text { Hasil } \\
\text { dehidrasi }\end{array}$ \\
\hline ALB (\%) & 1,667 & 1,855 \\
\hline Bilangan Peroksida(MekO $\left.{ }_{2} / \mathrm{Kg}\right)$ & 10,229 & - \\
\hline Bilangan Hidroksida $(\mathrm{mg} / \mathrm{g})$ & - & $28,27 \mathrm{mg} / \mathrm{g}$ \\
\hline Bilangan Iodium $\left(\mathrm{gI}_{2} / 100 \mathrm{~g}\right)$ & 7,7080 & 7,7080 \\
\hline
\end{tabular}

\subsection{Komposisi Minyak Kelapa}

Hasil analisis dengan GC-MS diperoleh dua data yaitu Kromatogram yang berasal dari hasil analisis GC dan spectra massa dari hasil analisis MS.Hasil dalam bentuk kromatogram dapat dilihat pada gambar 1 .

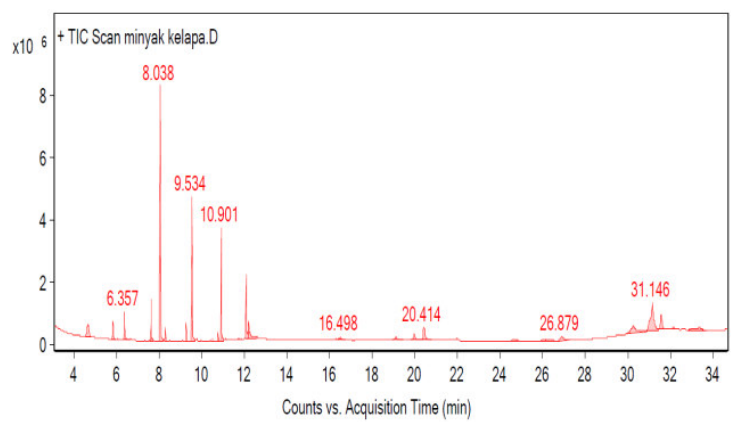

Gambar 1. Kromatogra GCMS Minyak Kelapa

Berdasarkan hasil analisa GCMS minyak kelapa, diperoleh komposisi asam lemak kelapa yang tertera pada Tabel 2.

Tabel 2. Kandungan Asam Lemak Minyak Kelapa

\begin{tabular}{|lc|c|}
\hline \multicolumn{2}{|c|}{ Komposisi Asam Lemak } & Kadar (\%) \\
\hline Asam kaprat $\quad\left(\mathrm{C}_{10} \mathrm{H}_{20} \mathrm{O}_{2}\right)$ & 2,78 \\
\hline Asam sitronelat $\quad\left(\mathrm{C}_{10} \mathrm{H}_{18} \mathrm{O}_{2}\right)$ & 2,58 \\
\hline Asam laurat $\quad\left(\mathrm{C}_{12} \mathrm{H}_{24} \mathrm{O}_{2}\right)$ & 24,13 \\
\hline Citronellyl asetat $\quad\left(\mathrm{C}_{12} \mathrm{H}_{22} \mathrm{O}_{2}\right)$ & 1,14 \\
\hline Asam miristat $\quad\left(\mathrm{C}_{14} \mathrm{H}_{28} \mathrm{O}_{2}\right)$ & 11,64 \\
\hline Asam palmitat $\quad\left(\mathrm{C}_{16} \mathrm{H}_{32} \mathrm{O}_{2}\right)$ & 7,42 \\
\hline Asam oleat $\quad\left(\mathrm{C}_{18} \mathrm{H}_{34} \mathrm{O}_{2}\right)$ & 5,26 \\
\hline Asam stearat $\quad\left(\mathrm{C}_{18} \mathrm{H}_{36} \mathrm{O}_{2}\right)$ & 3,42 \\
\hline Asam Docosanoic $\left(\mathrm{C}_{29} \mathrm{H}_{54} \mathrm{O}_{6}\right)$ & 11,93 \\
\hline Cyclohexylacetic acid & 2,39 \\
\hline Dan lainnya & 26,31 \\
\hline
\end{tabular}

\subsection{Dehidrasi Minyak Kastor}

Hasil analisis dengan GC-MS diperoleh dua data yaitu Kromatogram yang berasal dari hasil analisis GC dan spectra massa dari hasil analisis MS.Hasil dalam bentuk kromatogram dapat dilihat pada gambar 2 .

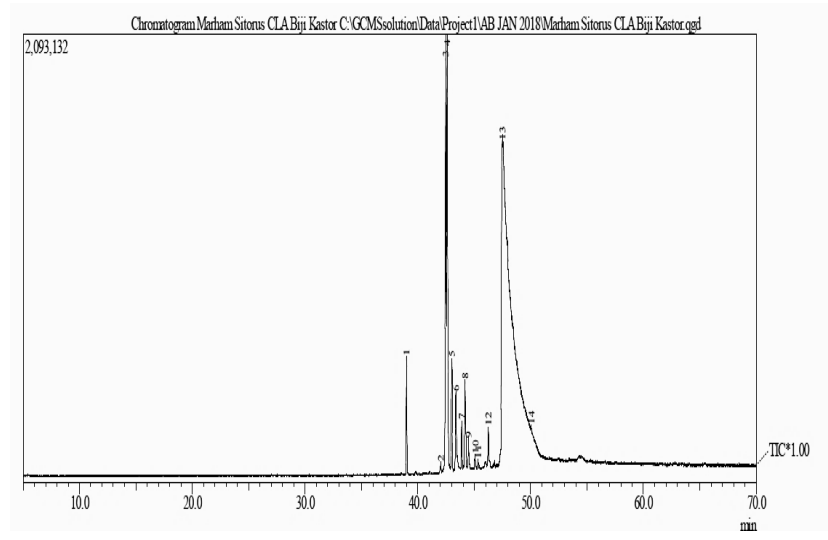

Gambar 2. Kromatogra GCMS Minyak Kelapa

Berdasarkan hasil analisa GCMS minyak kelapa, diperoleh komposisi asam lemak kelapa yang tertera pada Tabel 3 .

Tabel 3. Kandungan Asam Lemak Minyak Kelapa

\begin{tabular}{|l|c|}
\hline \multicolumn{1}{|c|}{ Komponen } & Kadar (\%) \\
\hline$(9 \mathrm{c}-12 \mathrm{c})$ Linoleat & 1,02 \\
\hline$(9 \mathrm{c} / \mathrm{t}-12 \mathrm{t} / \mathrm{c})$ Linoleat & 41,97 \\
\hline (9c/t-12t/c) CLA & 19,50 \\
\hline (9t-12t) Linoleat & 4,89 \\
\hline (9t-11t) CLA & 19,79 \\
\hline Ricinoleat & 0,94 \\
\hline
\end{tabular}

\subsection{Pembuatan Pengganti Mentega Coklat}

Hasil interesterifikasi minyak kastor hasil dehidrasi dan minyak kelapa untuk setiap variasi menunjukkan ciri-ciri yang sama yaitu berwarna putih kekuningan dan yang berbeda adalah tekstunya. Terdapat perbedaan cukup signifikan pada tekturnya, dimana semakin banyak minyak kastor maka hasil yang didapat semakin kental.

\subsection{Penentuan Titik Lebur}

Titik Lebur Pengukuran titik lebur dari hasil interesterifikasi anatara minyak kastor hasil dehidrasi dengan minyak kelapa dalam perbandingan (50:50);(60:40);(70:30);(80:20) dan (90:10) adalah seperti pada tabel 4 .

Tabel 4. Kandungan Asam Lemak Minyak Kelapa

\begin{tabular}{|c|c|c|}
\hline No & Jenis Bahan & $\begin{array}{c}\text { Titik Lebur } \\
\left({ }^{0} \mathrm{C}\right)\end{array}$ \\
\hline 1 & Minyak Kastor & -12 \\
\hline 2 & Minyak Kelapa & 25 \\
\hline 3 & M. Kastor + M. Kelapa (50:50) & 33 \\
\hline 4 & M. Kastor + M. Kelapa (60:40) & 30 \\
\hline
\end{tabular}




\begin{tabular}{|c|c|c|}
\hline 5 & M. Kastor + M. Kelapa (70:30) & 27 \\
\hline 6 & M. Kastor + M. Kelapa (80:20) & 26 \\
\hline 7 & M. Kastor + M. Kelapa (90:10) & 26 \\
\hline
\end{tabular}

Dari tabel 4 dapat dilihat bahwa titik lebur hasil reaksi interesterifikasi antara minyak kastor hasil dehidrasi dengan minyak kelapa pada perbandingan $(50: 50) ;(60: 40) ;(70: 30) ;(80: 20)$ dan (90:10) \% v/v adalah : $33^{0} \mathrm{C}, 30^{\circ} \mathrm{C}, 27^{0} \mathrm{C}, 26^{\circ} \mathrm{C}$, $26^{\circ} \mathrm{C}$. Minyak atau lemak yang telah mengalai interesterifikasi ternyata memiliki titik leleh yang lebih tinggi bila dibandingkan minyak atau lemak tunggal sebelum interesterifikasi. Terjadinya perubahan titik lebur setelah reaksi interesterifikasi diduga erat hubungannya dengan terjadinya pembentukan trigliserida-trigliserida baru, hasil penataan ulang molekul-molekul asam lemak pada minyak atau lemak semula. Penelitian ini bertujuan untuk membuat pengganti mentega coklat (cocoa butter substituent/CBS) yang syarat utamanya padat pada suhu kamar $\left(27{ }^{\circ} \mathrm{C}\right)$ dan melebur pada suhu $32-35{ }^{0} \mathrm{C}$. Berdasarkan pengukuran titik lebur pada proses interesterifikasi antara minyak kastor hasil dehidrasi dengan minyak kelapa maka perbandingan 50:50 adalah yang memenuhi syarat yaitu dengan titik leleh $33^{\circ} \mathrm{C}$.

\subsection{Komposisi Asam Lemak Hasil Interesterifikasi}

Berdasarkan hasil analisa GCMS hasil interesterifikasi minyak kastor hasil dehidrasi dengan minyak kelapa perbandingan 50:50\% $\mathrm{v} / \mathrm{v}$, hasil dalam bentuk kromatogram dapat dilihat pada gambar 4.3

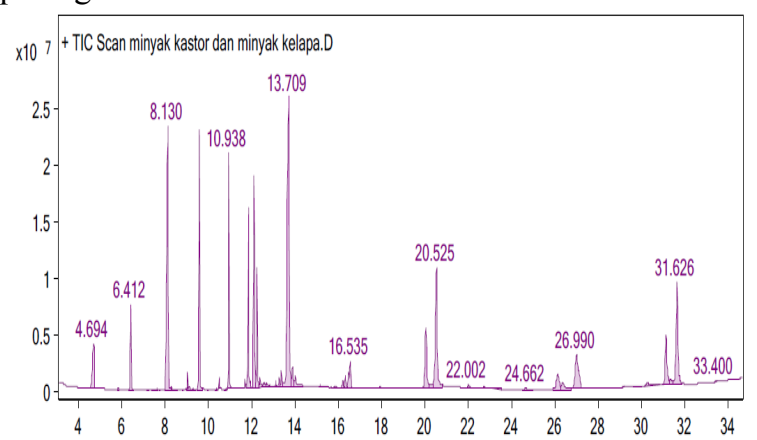

Gambar 3. Kromatogram GCMS Hasil Interesterifikasi

Berdasarkan hasil analisa GCMS minyak kelapa, diperoleh komposisi asam lemak kelapa yang tertera pada Tabel 5 .
Tabel 5. Perbandingan Kandungan Asam Lemak Pengganti Mentega Coklat dan Lemak Coklat

\begin{tabular}{|ll|c|}
\hline \multicolumn{2}{|c|}{$\begin{array}{c}\text { Komposisi Asam Lemak } \\
\text { Pengganti Mentega Coklat }\end{array}$} & $\begin{array}{c}\text { Jumlah } \\
\text { (\%) }\end{array}$ \\
\hline Asam kaprat & $\mathrm{C}_{10} \mathrm{H}_{20} \mathrm{O}_{2}$ & 2,26 \\
\hline Asam laurat & $\mathrm{C}_{12} \mathrm{H}_{24} \mathrm{O}_{2}$ & 14,5 \\
\hline Asam miristat & $\mathrm{C}_{14} \mathrm{H}_{28} \mathrm{O}_{2}$ & 8,01 \\
\hline Asam palmitat & $\mathrm{C}_{16} \mathrm{H}_{32} \mathrm{O}_{2}$ & 4,56 \\
\hline Asam oleat & $\mathrm{C}_{18} \mathrm{H}_{34} \mathrm{O}_{2}$ & 7,89 \\
\hline Asam stearat & $\mathrm{C}_{18} \mathrm{H}_{36} \mathrm{O}_{2}$ & 2,26 \\
\hline Asam Linoleat & $\mathrm{C}_{18} \mathrm{H}_{32} \mathrm{O}_{2}$ & 19,22 \\
\hline Dioktanoin & $\mathrm{C}_{19} \mathrm{H}_{36} \mathrm{O}_{5}$ & 7,59 \\
\hline Dilaurin & $\mathrm{C}_{27} \mathrm{H}_{52} \mathrm{O}_{5}$ & 6,28 \\
\hline Monolaurin & $\mathrm{C}_{15} \mathrm{H}_{30} \mathrm{O}_{4}$ & 4,02 \\
\hline Dan lainnya & & 23,41 \\
\hline
\end{tabular}

Komposisi asam lemak pengganti lemak coklat dari hasil interesterifikasi minyak kastor hasil dehidrasi dengan minyak kelapa dengan perbandingan 50:50 ini, asam lemak yang terbesar yaitu asam linoleat atau yang dikenal dengan nama omega-6 sebesar $(19,22 \%)$ dan asam laurat $(14,5 \%)$

\section{Kesimpulan}

Dari hasil pembahasan dapat disimpulkan bahwaminyak kelapa yang dihasilkan pada penelitan ini memiliki kualitas mutu II menurut SNI 01- 3741-2002 dengan ALB sebesar 1,667\%, Bilangan Peroksida 10,229 $\mathrm{MekO}_{2} / \mathrm{Kg}$ dan Bilangan Iodium 7,7080 $\mathrm{gI}_{2} / 100 \mathrm{~g}$.Hasil Interesterifikasi optimal pada perbandingan minyak kastor hasil dehidrasi dengan minyak kelapa (50: 50) $\mathrm{v} / \mathrm{v}$ dengan titik leleh $33^{\circ} \mathrm{C}$ sesuai dengan lemak kakao standar yaitu $\left(32^{\circ} \mathrm{C}-35^{\circ} \mathrm{C}\right)$.

Berdasarkan kromatogram GC-MS maka hasil interesterifikasi mengandung asam linoleat (omega-6) sebesar 19,22\% dengan demikian pengganti mentega coklat yang dihasilkan kaya akan linoleat (omega-6). Hasil interesterifikasi potensial sebagai pengganti minyak kakao dengan pengkajian lebih mendalam.

\section{Acknowledgement}

Ucapan terima kasih penulis ucapkan kepada Laboratorium Kimia Universitas Negeri Medan yang telah mengizinkan penulis melakukan penelitian. Penulis juga mengucapkan terimkasi kepadaBapak Dr. Marham Sitorus, M.Si yang telah banyak memberi masukan dan bimbingan kepada penulis selama melakukan penelitian. Terimaksikasih kepada orangtua penulis yang selalu memberikan doa, motivasi, nasehat, 
dukungan serta kasih sayang yang tidak terhingga yang diberikan kepada penulis dari mulai perkuliahan hingga menyelesaikan penelitian ini.

\section{Referensi}

1. Ginting, E.(1995). Sintesis 12-(kloro)-metil okta Deka-9-ene-1-1oat Dari Minyak Jarak (Ricinus Comunnis Linn) Melalui Reaksi interestifikasi dan Klorinasi. Jurusan Kimia FMIPA USU : Medan

2. Kusdianti dan Meirandi, E.R.(2005).Tinjauan Tentang Bunga Jarak (Ricinus Communis Linn). Jurusan Pendidikan Biologi Fakultas Pendidikan Matematika Dan Ilmu Pengetahuan Alam. UPI : Bandung

3. Ketaren, S., (1986), Penghantar Teknologi Minyak dan Lemak Pangan, UI Press, Jakarta

4. Kusumaningsih, T, Saryoso, R.(2006).Bioteknoogi 3 (1) : 20-26 Mei 2006, ISSN : 0216-6887. Kimia FMIPA. UNS

5. Sitorus, M.(2011). Kajian Transformasi Risonoleat Minyak Jarak Menjadi Asam Linoleat Terkonjugasi Melalui Reaksi Dehidrasi Dan Isomerasi.Disertasi. Program Doktor Paska Sarjana. Universitas Andalas

6. Mawarni, R.(2006). Asam Linoleat Terkonjugasi Penurun Timbunan Lemak. Pusat Kajian Makanan Dan Obat Tradisional; Lembaga Penelitian UNDIP. Semarang

7. Oktavianis, T dan Sofiyanita.(2019). Making Bioethanol From Cocoa Fruit Skin Waste By Hydrolysis Process Using Trichoderma Viride Mold. Indonesian Journal of Chemical Science and Technology 2 (1), pp. 85-79

8. O'Brien, R.D.(2008). Fats and Oils, Formulating and Processing For Aplication, Edition second, Technomic Publishing Company, Inc. USA.

9. Sari, S.S., Putri, T.K., AR, M.R.(2019). Effect of Dragon Fruit Juice Addition on Changes in Peroxide Numbers and Acid Numbers of Used Cooking Oil. Indonesian Journal of Chemical Science and Technology2 (2), pp. 136-141

10. Shukla, V, K, S.(1996).Chocolate the Chemistry of Pleasure. INFORM. 8(2) February

11. Sinaga, M.(2006).Ricinus Communis inn. Pusat Penelitan dan Pengembangan Tanaman Obat UNAS/ $\mathrm{P}_{3}$ TO Jakarta

12. Sitorus M, Ibrahim S, Nurdin H \& Darwis D. (2009). Transformation of Ricinoleic of Castor Oil into Linoleic Acid (Omega-6) and Conjugated Linoleic Acid. Indonesian Journal of Chemistry 9 (2), pp. $278-284$ 